\title{
Population dynamics of rice leaffolders (Lepidoptera: Pyralidae) and their natural enemies in irrigated rice in the Philippines
}

\author{
J. de Kraker ${ }^{1,2}$, A. van Huis ${ }^{2}$, K.L. Heong ${ }^{3}$, J.C. van \\ Lenteren $^{2}$ and R. Rabbinge ${ }^{1}$ \\ ${ }^{1}$ Laboratory of Theoretical Production Ecology, Wageningen Agricultural \\ University, PO Box 430, 6700 AK Wageningen, The Netherlands: \\ ${ }^{2}$ Laboratory of Entomology, Wageningen Agricultural University, \\ Wageningen, The Netherlands: ${ }^{3}$ International Rice Research Institute, Los \\ Baños, Philippines
}

\begin{abstract}
Populations of rice leaffolders and their natural enemies were studied in eight crops of irrigated rice in Laguna Province, the Philippines. The rice leaffolder complex consisted of three species: Cnaphalocrocis medinalis (Guenée), Marasmia patnalis Bradley and M. exigua Butler. Leaffolder population dynamics were characterized by an egg peak at maximum tillering and a broad larval peak around booting stage. Peak densities ranged from 0.2 to 2.0 larvae per hill. Most larvae originated from immigrant moths and there was no substantial second generation. The seasonal percentage egg parasitism by Trichogramma sp. ranged from 0 to 27\%, and percentage larval parasitism from 14 to 56\%. The braconid Macrocentrus philippinensis Ashmead was the most commonly reared larval parasitoid. Forty natural enemy taxa that may attack rice leaffolders were identified from suction and sweepnet samples: 24 predator taxa and 16 parasitoid taxa. The estimated survival rates from leaffolder egg to larval stages and between larval stages showed large variation between rice crops, but were not clearly correlated with observed levels of parasitism, natural enemy abundance, or natural enemy to leaffolder ratios. It is suggested that the generally low densities of rice leaffolders in Philippine transplanted rice are caused by their ovipositional preference for crops at the maximum tillering stage, allowing for only one generation, and by high immature mortality caused by the abundant and diverse complex of natural enemies.
\end{abstract}

\section{Introduction}

Since the mid-1960s, rice leaffolders Cnaphalocrocis medinalis (Guenée) and Marasmia spp. (Lepidoptera: Pyralidae) have increased in abundance, and in many Asian countries they are now considered as important pests

*Fax: +31 317484892

E-mail: joop.dekraker@staff.tpe.wau.nl
(Reissig et al., 1986; Khan et al., 1988; Dale, 1994). The shift from minor to major pest status has been attributed to the adoption of new rice growing practices that accompanied the introduction of high yielding varieties (Kulshreshtha et al., 1970; Litsinger, 1989). Rice leaffolder larvae cause conspicuous injury by folding leaves and scraping off the green mesophyll tissue, and farmers usually respond by applying insecticides, even at very low infestation levels (Heong et al., 1994). However, in many cases it is questionable whether chemical control of rice leaffolder is 
Table 1. Details of field studies on the population dynamics of rice leaffolders and their natural enemies, Laguna, Philippines.

\begin{tabular}{|c|c|c|c|c|c|c|c|c|c|c|c|c|c|}
\hline \multirow{2}{*}{ Location } & \multirow{2}{*}{$\begin{array}{l}\text { Area } \\
\text { (ha) }\end{array}$} & \multirow{2}{*}{ Variety } & \multirow{2}{*}{ Year-season } & \multirow{2}{*}{$\begin{array}{c}\text { Transplanting } \\
\text { date }\end{array}$} & \multicolumn{3}{|c|}{ Hill samples } & \multicolumn{3}{|c|}{ Suction samples } & \multicolumn{3}{|c|}{ Sweepnet samples } \\
\hline & & & & & Size & No. & Period & Size & No. & Period & Size & No. & Period \\
\hline Victoria & 0.49 & R-10 & 1991 dry & 12 January & 50 & 5 & $(4-12)$ & 25 & 6 & $(2-12)$ & 20 & 6 & $(2-12)$ \\
\hline Pila & 0.62 & C-4 & 1991 dry & 4 January & 50 & 5 & (5-13) & 25 & 6 & $(3-15)$ & 20 & 7 & $(3-15)$ \\
\hline Pila & 0.20 & IR70 & 1991 wet & 31 August & 60 & 22 & $(4-16)$ & 20 & 12 & $(4-15)$ & 16 & 12 & $(5-16)$ \\
\hline Pila & 0.34 & $C-4$ & 1992 dry & 27 January & 100 & 9 & $(5-$ & 24 & 3 & $(6-10)$ & 20 & 6 & $(5-14)$ \\
\hline Pila & 0.34 & IR72 & 1993 dry & 4 February & 100 & 8 & (3-13) & 25 & 10 & $(3-13)$ & - & - & - \\
\hline Pila & 0.34 & IR72 & 1993 wet & 16 August & 50 & 4 & $(4-12)$ & 30 & 4 & $(4-12)$ & - & - & - \\
\hline IRRI & 0.25 & IR72 & 1992 wet & 23 June & 30 & 7 & (3-14) & 15 & 6 & $(3-14)$ & 10 & 5 & $(4-12)$ \\
\hline IRRI & 0.25 & IR72 & 1993 wet & 17 July & 50 & 3 & $(7-9)$ & 30 & 3 & $(7-9)$ & - & - & - \\
\hline
\end{tabular}

For each of the three sampling methods 'size' (no. of sampling units per sample), 'no.' (number of sampling dates) and 'period' (period during which samples were taken, in weeks after transplanting) are given. Sampling units were one hill for hill samples, four hills covered by an enclosure for suction samples and five sweeps for sweepnet samples; -, no samples collected.

justified, despite its increased abundance. Modern rice varieties have a high tolerance to defoliation (IRRI, 1993), and tropical rice fields harbour a large complex of natural enemies, that may keep rice leaffolder populations below damaging levels most of the time (Khan et al., 1988; Barrion et al., 1991).

Knowledge of rice leaffolder population dynamics, and insight into the factors determining leaffolder abundance, such as natural enemies, is essential as a basis for more rational pest management. Rice leaffolder population dynamics have been well-studied in China and Japan, where the pest is mainly migratory with distinct generations (Liang \& Pang, 1987; Wada \& Kobayashi, 1991; Zhang, 1991). In tropical Asia, where leaffolders reproduce year-round, their population dynamics have rarely been studied in detail. Infestation levels are usually reported only as percentage injured leaves and few studies deal with factors affecting population densities. Most reports on the impact of natural enemies concern percentages of larval parasitism, while relationships between natural enemy abundance and leaffolder infestation levels have not been established.

In this paper, results are presented of a study of the population dynamics of rice leaffolders and their natural enemies in eight crops of rice in the Philippines. The objective was to characterize the population dynamics of the leaffolder complex, and to obtain insight into the factors determining their temporal abundance and survival during a crop season. The study focused on the role of natural enemies in leaffolder population dynamics. Therefore, the dynamics of leaffolder natural enemies and leaffolder parasitism rates were determined in relation to leaffolder abundance and survival rates. The results of the study are discussed in view of leaffolder pest management.

\section{Materials and methods}

\section{Description of study area and fields}

The study was conducted in Laguna Province, the Philippines, a humid tropical lowland area where rice is grown year-round under irrigated conditions. The rice leaffolder population in Laguna is a complex of three related species: C. medinalis, Marasmia patnalis Bradley, and M exigua Butler (Lepidoptera: Pyralidae) (Arida \& Shepard, 1986). The first two species are the most abundant in Laguna, but dominance by any one species can vary during a crop season (Barrion et al., 1991).
Field work was carried out in eight crops of irrigated rice, covering three sites and six seasons (table 1). One of the sites was a field at the experimental farm of the International Rice Research Institute (IRRI) in Los Baños $\left(13^{\circ} 14^{\prime} \mathrm{N}, 121^{\circ} 15^{\prime} \mathrm{E}\right)$. The two other sites (Pila and Victoria) were farmers' fields at 15-20 km distance from IRRI. Two-week-old seedlings of a variety susceptible to leaffolder were transplanted to the fields in a $20 \times 20 \mathrm{~cm}$ spacing. The crops received fertilizer at a rate of $c .90 \mathrm{~kg} \mathrm{~N} \mathrm{ha}^{-1}$, according to standard recommendations. Weeding was done by hand and pesticides were not applied. The IRRI field was kept permanently flooded until a week before harvest, while the farmers' fields in Pila and Victoria were intermittently flooded. Rice yields were between 4 and 7 tons per hectare.

\section{Arthropod sampling}

The densities of rice leaffolder stages and their natural enemies were estimated by a combination of sampling methods (table 1). Rice leaffolder moths and arthropod natural enemies were sampled with a suction sampler (DVac or Blower-Vac, Arida \& Heong, 1992) in combination with a plastic bucket enclosure, covering four hills. To include fast-moving insects like orthopterans, the enclosure was quickly placed over the hills. Relative density estimates of highly mobile species, such as the larger hymenopterous parasitoids and Odonata, were obtained by sweepnet sampling in five of the eight crops. Suction and sweepnet samples were taken between 08.00 and $11.00 \mathrm{~h}$. Predators and parasitoids of rice leaffolders were counted using a checklist based on the Philippine rice leaffolder foodweb (Barrion et al., 1991).

The densities of the immature leaffolder stages were estimated by randomly sampling rice hills and examining them in the laboratory for the presence of leaffolder eggs, larvae and pupae and leaves injured by leaffolder larvae. Larvae were classified in five size-classes, approximately corresponding with the five larval instars. The immature stages were kept in test tubes or Petri dishes until emergence of adults or parasitoids, or until premature death. Leaffolders were identified to species only after moth emergence, because the immature stages of $C$. medinalis and Marasmia spp. are morphologically very difficult to distinguish (Barrion et al., 1991). The moths can be easily identified to species by their wing markings (Barrion \& Litsinger, 1985). 
Ratios of natural enemy to rice leaffolder density were calculated for moths, immatures, and larvae separately, using absolute estimates (number per hill) from hill and suction samples. Within the natural enemy complex attacking leaffolders, Odonata and Araneae were classified as moth predators, while Coleoptera, Orthoptera and Hemiptera were classified as predators of leaffolder immatures (Barrion et al., 1991). For each crop, natural enemy to leaffolder ratios were calculated over three consecutive periods of five weeks, representing the vegetative, reproductive and ripening stage (Yoshida, 1981). Also the seasonal averages of these ratios were calculated.

\section{Parasitism}

Absolute estimates of parasitoid impact on a host population are difficult to obtain and usually require recruitment data in addition to host population samples (van Driesche et al., 1991). In this study, such additional data were not collected and therefore a seasonal level of parasitism was calculated only as an indicator of parasitoid impact. As the eggs, larvae and pupae are protected from parasitoids during their remaining period of development by taking them out of the field, this method underestimates the potential parasitoid impact (van Driesche, 1983). The indicator may be improved by correction for differences between healthy and parasitized hosts in development time, mortality rate, or sampling efficiency (van Driesche, 1983), but we lacked the detailed biological knowledge to do this. The seasonal percentage parasitism of eggs and larvae was simply calculated by dividing the number of hosts with clear symptoms of parasitism by the total number of hosts, after pooling the samples per crop season. Immature leaffolders that died of unknown cause, were excluded from the calculation on the assumption that healthy and parasitized hosts had similar chances of dying.

\section{Survival rates}

From the time series of leaffolder population samples per crop, estimates were made of stage to stage survival rates. A large number of methods has been developed to calculate stage-specific survival rates from stage-frequency data (Manly, 1989), but most of these methods require initial recruitment data or make the usually unrealistic assumption that the daily or stage-specific survival rate is constant. A simple and well-known method that does not have these limitations, is Southwood and Jepson's 'graphical method' (Southwood, 1978). Per stage, the number alive mid-way is calculated by dividing the area under the density curve by the stage-specific development time. As this method implies that all mortality occurs at the end of the stage, no truly stage-specific survival rates can be obtained. The survival from mid-way stage $i$ till midway stage $i+1$ is estimated by dividing the number in stage $i+1$ by those in stage $i$.

For seven leaffolder populations, survival rates were calculated from egg to larva, egg to medium-sized larva (L2, L3), and from medium-sized larva to large larva (L4, L5, L6). Data on pupal densities were insufficient to include in the analysis. An average duration of four days was taken for the egg stage, five days for the medium-sized larvae and 11 days for the large larvae. The three leaffolder species differ only slightly in stage durations (Barrion et al., 1991). Duration depends primarily on temperature, and in the case of larvae also on host plant quality (Wada \& Kobayashi, 1980). However, ambient temperature was fairly constant under the conditions studied, and host-plant effects on larval development are relatively small (Wada, 1979; de Kraker, unpublished), justifying the use of standard durations. The densities of the various leaffolder stages were adjusted according to their sampling efficiency. A previous experiment showed that relative to large larvae, sampling eggs was c. $50 \%$ efficient, and sampling medium-sized larvae c. 60\%. Sampling efficiency of the cryptic and tiny first instar larvae is very low, and therefore this stage was excluded from the survival analysis. The calculated stage to stage survival rates are approximate values, primarily meant for comparison between crops and correlation with other variables.

\section{Correlation analysis}

A correlation analysis was applied to identify significant associations between the observed or derived variables of the leaffolder-natural enemy system. Such correlations can indicate potentially important factors in the natural control of leaffolders, such as density dependency and strong trophic linkages, and serve to guide more detailed research into the underlying causal mechanisms. Simple linear correlation coefficients were computed between the following variables in a matrix, using one seasonal value per crop $(n \leq 8)$ : proportion of each leaffolder species, abundance of leaffolder stages (average density, area under the density curve, recruitment per hill), eggs-moth ratio, stage to stage survival rates, percentages egg and larval parasitism, abundance of natural enemy groups, and natural enemy-leaffolder ratios. In addition, $x-y$ plots of the correlated variables were inspected to check for obvious non-linear relationships.

\section{Results \\ Rice leaffolder population dynamics and injury}

Two leaffolder species, C. medinalis and M. patnalis, were found in all eight crops of rice, while a third species, M. exigua, was found in five crops. In most crops, C. medinalis appeared first, soon followed by M. patnalis, while M. exigua was usually last. The percentage of the seasonal total made up by any of the three species was quite variable (fig. 1): for C. medinalis it ranged from 11 to $88 \%$, for M. patnalis from 17 to $89 \%$, and for M. exigua from 0 to $33 \%$ (adult stage, suction samples). Either C. medinalis or M. patnalis was dominant, or both were equally abundant.

Rice leaffolder moths usually first appeared four weeks after transplanting, but the timing of the peak densities did not follow a consistent pattern (fig. 2). Eggs peaked around maximum tillering stage ( 7 weeks after transplanting), with a broad larval peak following one or two weeks later, at booting stage (fig. 2). After the flowering stage only few eggs were found. Peak larval densities ranged from 0.2 to 2.0 hill $^{-1}$. Only a few pupae and pupal cases were found in the samples, and peak densities were below 0.2 hill $^{-1}$. Pupae are difficult to find, because leaffolder larvae often pupate behind leaf sheaths.

Leaf injury due to rice leaffolder larvae became visible after four weeks after transplanting. The number of injured leaves per hill peaked around flowering, and decreased towards maturity due to leaf senescence (fig. 2). Peak levels 


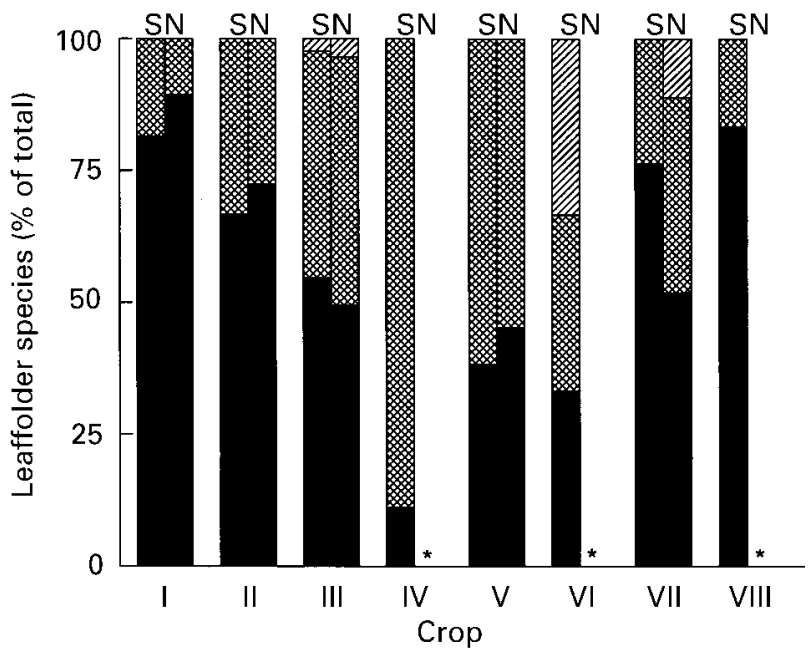

Fig. 1. Rice leaffolder species composition ( $\mathbf{\square}$, Cnaphalocrocis medinalis; $\mathbb{x}^{2}$ Marasmia patnalis;, M. exigua) in four dry season crops (I, Victoria 1991; II, Pila 1991; III, Pila 1992; IV, Pila 1993), and four wet season crops (V, Pila 1991; VI, Pila 1993; VII, IRRI 1992; VIII, IRRI 1993), Laguna, Philippines. The percentage per leaffolder species represents its share in the seasonal total catch of moths (S, suction samples; N, sweepnet; asterisk, no samples collected). For both methods, species composition differed significantly between crops (G-test of independence, $P<0.001$ ).

of injured leaves per hill ranged from 0.7 to 10.6 , and were higher in the wet season than in the dry season. The percentage of injured leaves per hill was approximately the same as the number, as there were about 100 leaves per hill. Leaf injury per crop was positively correlated with larval infestation level $(r=0.8, P<0.05$, both variables calculated as area under the density curve).

\section{Composition and abundance of leaffolder natural enemy complex}

Forty leaffolder natural enemy taxa were identified from the arthropod samples: 24 predator and 16 parasitoid taxa (for details on species, see: de Kraker, 1996). The differences between the eight crops of rice were only moderate in terms of number of taxa found per crop. This number ranged from 24 (IRRI 1992-WS) to 36 (Pila 1993-DS) in the suction samples, and from 24 (IRRI 1992-WS) to 31 (Pila 1991-DS) in the sweepnet samples. Combining both methods usually resulted in more taxa per crop, as the sampling methods are partly complementary and a larger sampling effort also increases the chance of collecting more taxa. During a crop season, the number of leaffolder natural enemy taxa reached a maximum level at about the maximum tillering stage, and then stabilized or decreased slowly towards maturity. Both sampling methods yielded this same pattern.

The most common predator species, both in terms of incidence and abundance, were the spiders Pardosa pseudoannulata (Boesenberg \& Strand) (Araneae: Lycosidae) and Tetragnatha spp. (Araneae: Tetragnathidae), the beetles Ophionea nigrofasciata Schmidt-Goebel (Carabidae) and Micraspis sp. (Coccinellidae), the orthopterans Conocephalus longipennis (de Haan) (Tettigoniidae), Anaxipha longipennis (Serville) (Gryllidae) and Metioche vittaticollis (Stål) (Gryllidae), and the hemipterans Cyrtorhinus lividipennis Reuter (Miridae), Microvelia douglasi atrolineata Bergroth (Veliidae), Mesovelia vittigera Horvath (Mesoveliidae) and Polytoxus fuscovittatus (Stål) (Reduviidae). Predator populations were numerically dominated by the hemipterous species (fig. 3). Cyrtorhinus lividipennis dominated during the dry season, and M. d. atrolineata in the wet season crops. In terms of predator biomass this picture would be very different, as the individual weight of the dominant hemipterans is only $5-10 \%$ of the weight of the spiders, beetles or orthopterans. Temporal trends in abundance varied per crop for spiders and hemipterans, while the numbers of coleopteran and orthopteran predators were always highest during the last part of the crop season (fig. 3) The ratio of predators (Odonata, Araneae) to leaffolder moths ranged from 3 to 19, while the number of predators (Coleoptera, Orthoptera and Hemiptera) per leaffolder immature varied from 2 to 16 between crops. Excluding the hemipterans resulted in ratios of 0.4 to 2.4. Predator-prey ratios were usually lowest during the reproductive crop stage, mainly because then leaffolder densities were highest.

The abundance of the hymenopterous parasitoids is represented by counts from the sweepnet samples (fig. 4), because for these species this sampling method is more efficient. The parasitoids did not show a consistent pattern in abundance during the crop season. The most common taxa of larval hymenopterous parasitoids were Cotesia spp. (Braconidae), Opius spp. (Braconidae), and Tetrastichus spp. (Eulophidae). Six parasitoid species that accounted for $90 \%$ of parasitism of collected rice leaffolder larvae, viz. Macrocentrus philippinensis Ashmead (Braconidae), Cardiochiles philippinensis Ashmead (Braconidae), Copidosomopsis nacoleiae (Eady) (Encyrtidae), Temelucha philippinensis (Ashmead) (Ichneumonidae), Trichomma cnaphalocrocis Uchida (Ichneumonidae), and Goniozus sp. (Bethylidae), only made up a minor percentage $(7-26 \%)$ of the population of potential parasitoids (fig. 4). The parasitoid-leaffolder host ratio for these major species ranged from 0.05 to 0.40 per crop. The variation between crops in natural enemy to leaffolder ratios was large, but this was not associated with an inverse relationship between the average densities of leaffolder stages and the abundance of their natural enemies.

\section{Parasitism}

Eleven species of hymenopterous parasitoids were reared from the field-collected rice leaffolders: one from the eggs, ten from larvae and two from both larvae and pupae (table 2). It could not be determined from which leaffolder species parasitoids emerged, as the immature stages are morphologically very difficult to distinguish. Leaffolder larvae infected by entomopathogens were rarely observed in the samples or in the fields.

The seasonal percentage of eggs parasitized by Trichogramma sp., probably T. japonicum Ashmead (Trichogrammatidae), varied from 0 to $27 \%$ (table 3 ). This variation was independent of the average egg density per crop. Parasitism was lower during the wet season, probably due to the negative impact of wind and rain on parasitoid activity (Keller et al., 1985). During a growing season, percentage egg parasitism decreased steadily towards crop maturity. 

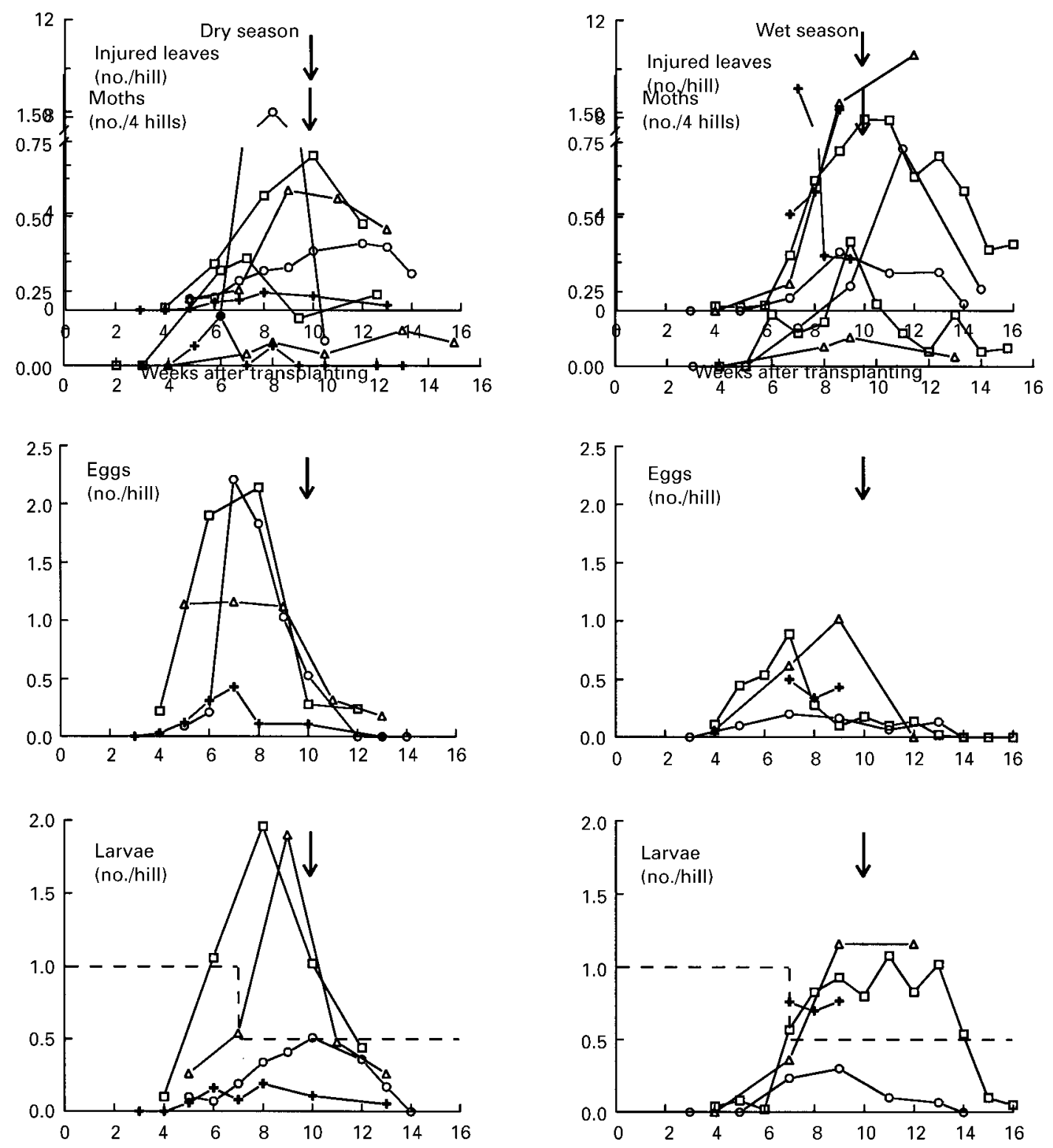

Fig. 2. Mean densities of rice leaffolder stages in four dry season rice crops ( $\square$, Victoria; $\triangle$, Pila 1991; $\bigcirc$, Pila 1992; +, Pila 1993), and four wet season crops ( $\square$, Pila 1991; $\triangle$, Pila 1993; O, IRRI 1992; + IRRI 1993), Laguna, Philippines. Arrow indicates rice flowering stage. Moths: suction samples; standard errors (S.E.) were c. 40\% of the sample means. Eggs: hill samples; S.E. c. 20\%. Larvae: hill samples; S.E. c. $20 \%$. Dashed line indicates the conservative action threshold (see text). Leaves with rice leaffolder injury: hill samples; S.E. c. $10 \%$. 

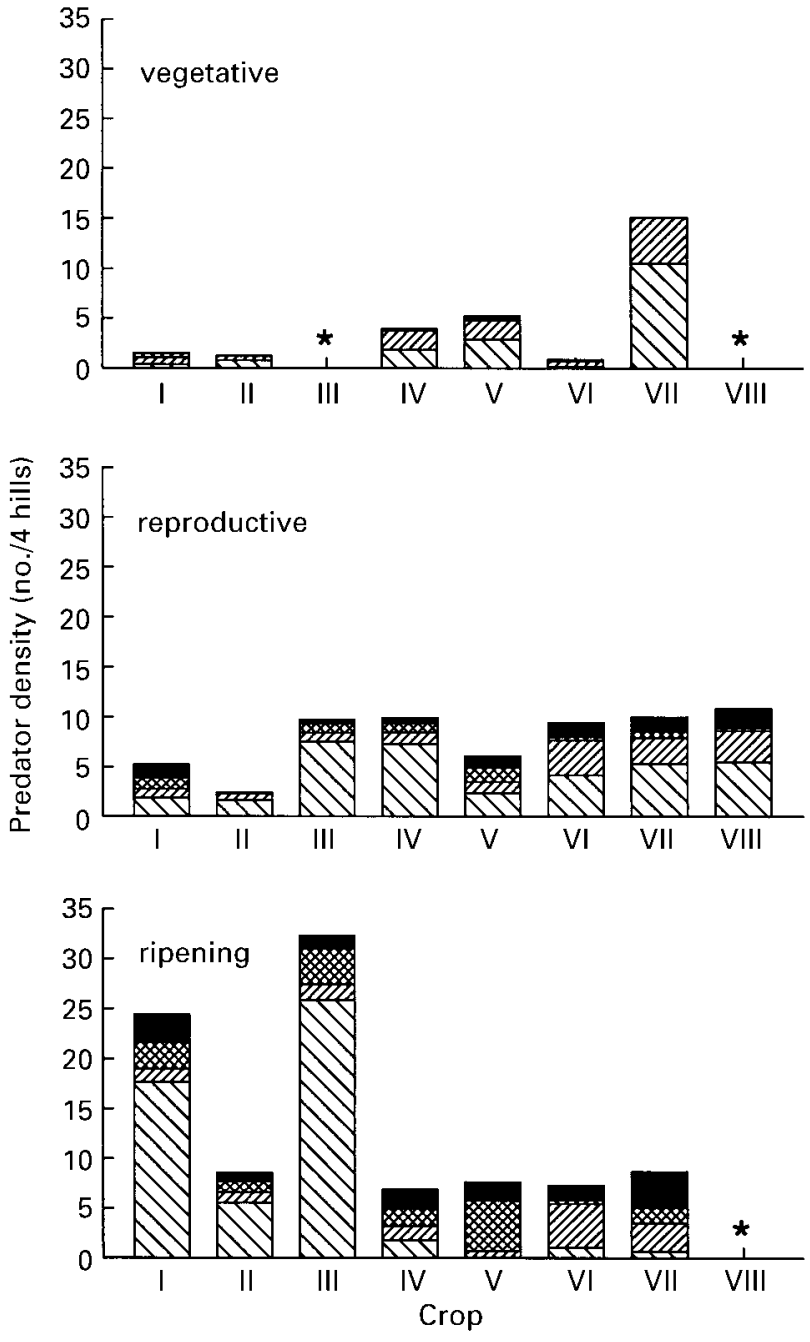

Fig. 3. Mean density of major predator groups of rice leaffolders during the three crop growth stages in four dry season crops (I, Victoria 1991; II, Pila 1991; III, Pila 1992; IV, Pila 1993), and four wet season crops (V, Pilla 1991; VI, Pila 1993; VII, IRRI 1992; VIII, IRRI 1993), Laguna, Philippines. Predators ( $\mathbb{Q}$, Hemiptera; $\mathbb{Z}$, Araneae; $⿴ 囗$, Coleoptera; $\mathbf{\square}$, Orthoptera) were sampled with a suction sampler. Asterisk: no samples collected.

Percentage larval parasitism ranged from 14 to $56 \%$ per crop (table 3). The level of parasitism was independent of the average larval density. There was no correlation between adult parasitoid abundance or parasitoid-host ratio and the level of parasitism. Percentage parasitism was usually highest in the last larval instars. Larval parasitism was relatively low at the start and at the end of the crop season. The species composition of the reared parasitoids was not related with crop growth stage.

The ranking of larval parasitoids according to their share in parasitism varied from crop to crop. Macrocentrus philippinensis was the most commonly reared parasitoid, followed by C. nacoleiae, and T. cnaphalocrocis. However, the last two species were probably over-represented, because C. nacoleiae has a longer development time than the other

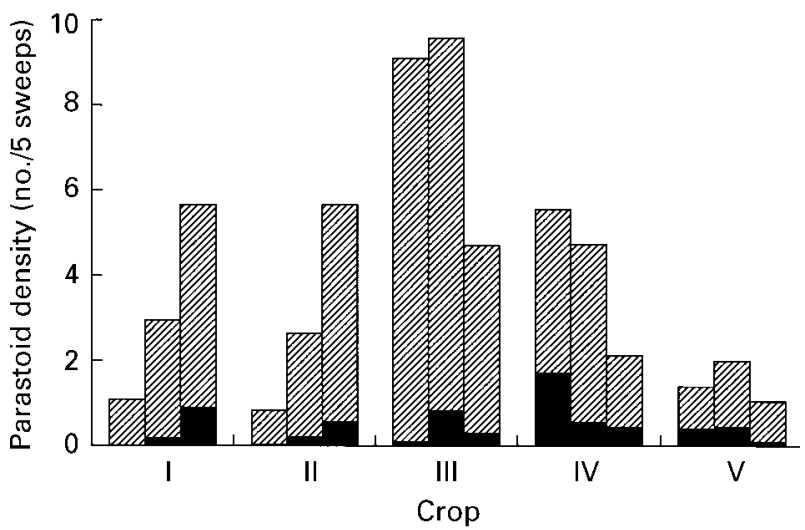

Fig. 4. Mean density of hymenopterous parasitoids of rice leaffolders during the three crop growth stages (vegetative, reproductive, ripening) in five rice crops (I, Victoria 1991-DS; II, Pila 1991-DS; III, Pila 1991-WS; IV, Pila 1992-DS; V, IRRI 1992-WS), Laguna, Philippines. Black part of each bar indicates the density of six parasitoid species, accounting for $90 \%$ of parasitism in larval samples. Parasitoids were sampled with a sweepnet.

parasitoids, while T. cnaphalocrocis occurs primarily in late larval instars. These instars were sampled more efficiently and survived better in the laboratory.

\section{Recruitment and survival rates}

The estimated seasonal recruitment of eggs ranged from 3 to 14 hill $^{-1}$ (table 4). Egg recruitment was not correlated with the abundance of leaffolders moths, and the number of eggs per moth ranged from less than 10 to more than 140 . This variation was independent of predator-prey ratio or abundance of moth predators and predators of immatures.

The survival rate from mid egg stage to mid large larval stage averaged 0.14 for five rice crops (range: 0.03-0.30, table 4). The sampling efficiency of eggs may have been lower than the value used for the calculations $(50 \%)$, because the survival rate from egg to medium-sized larva was larger than 1.0 in one crop (Pila 1991-WS). This implies that the level of egg recruitment was generally underestimated and that as a result, survival rates were overestimated.

The recruitment levels of eggs and larvae were statistically independent. The estimated survival rates from egg to larval stage, or from egg to medium-sized larva and from mediumsized larva to large larva, varied considerably between crops (table 4). The survival rates were not correlated with leaffolder species composition, egg or larval recruitment, nor with percentage egg parasitism, predator abundance or predator-prey ratio. Survival from medium-sized to large larva was higher in the wet season than in the dry season, and appeared to be negatively correlated with the percentage parasitism of the first three larval instars (tables 3 and 4).

\section{Discussion}

\section{Abundance of rice leaffolders during a crop season}

Rice leaffolders may complete two to three generations on a single rice crop, considering their generation time of 
Table 2. Parasitoid species reared from samples of rice leaffolder eggs, larvae, and pupae, Laguna, Philippines.

\begin{tabular}{|c|c|c|c|c|c|c|c|c|c|}
\hline \multirow[b]{2}{*}{ Family } & \multirow[b]{2}{*}{ Species } & \multirow[b]{2}{*}{ Host stage $^{\mathrm{a}}$} & \multicolumn{7}{|c|}{ Crop } \\
\hline & & & $\begin{array}{l}\text { VI } \\
91 \\
\text { DS }\end{array}$ & $\begin{array}{l}\text { PI } \\
91 \\
\text { DS }\end{array}$ & $\begin{array}{l}\text { PI } \\
92 \\
\text { DS }\end{array}$ & $\begin{array}{l}\text { PI } \\
91 \\
\text { WS }\end{array}$ & $\begin{array}{l}\text { PI } \\
93 \\
\text { WS }\end{array}$ & $\begin{array}{l}\text { IR } \\
92 \\
\text { WS }\end{array}$ & $\begin{array}{l}\text { IR } \\
93 \\
\text { WS }\end{array}$ \\
\hline Bethylidae & Goniozus sp. & larva & - & + & + & + & + & - & - \\
\hline Braconidae & $\begin{array}{l}\text { Cardiochiles philippinensis } \\
\text { Cotesia spp. } \\
\text { Macrocentrus philippinensis }\end{array}$ & $\begin{array}{l}\text { larva } \\
\text { larva } \\
\text { larva }\end{array}$ & $\begin{array}{l}- \\
* \\
+\end{array}$ & $\begin{array}{l}* \\
+ \\
-\end{array}$ & $\begin{array}{l}- \\
+ \\
*\end{array}$ & $\begin{array}{l}+ \\
+ \\
*\end{array}$ & $\begin{array}{l}+ \\
- \\
+\end{array}$ & $\begin{array}{l}- \\
- \\
*\end{array}$ & $\begin{array}{l}+ \\
+ \\
+\end{array}$ \\
\hline Chalcididae & Brachymeria sp. & larva & - & - & - & - & - & - & + \\
\hline Elasmidae & Elasmus sp. & larva & + & + & - & + & - & - & - \\
\hline Encyrtidae & Copidosomopsis nacoleiae & larva & - & - & + & + & + & - & * \\
\hline Eulophidae & Tetrastichus sp. & larva, pupa & - & - & - & + & - & - & + \\
\hline Ichneumonidae & $\begin{array}{l}\text { Temelucha philippinensis } \\
\text { Trichomma cnaphalocrocis }\end{array}$ & $\begin{array}{l}\text { larva } \\
\text { larva, pupa }\end{array}$ & $\begin{array}{l}+ \\
-\end{array}$ & $\begin{array}{l}+ \\
-\end{array}$ & $\begin{array}{l}+ \\
+\end{array}$ & $\begin{array}{l}+ \\
+\end{array}$ & + & $\begin{array}{l}- \\
-\end{array}$ & $\begin{array}{l}+ \\
+\end{array}$ \\
\hline Trichogrammatidae & Trichogramma sp. & egg & + & + & + & + & + & - & + \\
\hline
\end{tabular}

aStage collected in the field, host stage of attack or emergence may differ.

-, Absent; +, present; ${ }^{*}$, most common parasitoid in that crop; VI, Victoria; PI, Pila; IR, IRRI; DS, dry season; WS, wet season.

Table 3. Percentage parasitism of rice leaffolder eggs and larvae, pooled over a crop season, Laguna, Philippines.

\begin{tabular}{lcccc} 
Location & Year-season & Egg parasitism & \multicolumn{2}{c}{ Larval parasitism } \\
\cline { 3 - 5 } & & & L1-3 & L1-5 \\
\hline Victoria & 1991-DS & - & - & 26.7 \\
Pila & 1991-DS & - & - & 38.8 \\
Pila & 1992-DS & 27.3 & 46.8 & 43.8 \\
Pila & 1993-DS & 26.9 & - & - \\
Pila & 1991-WS & 17.6 & 27.4 & 31.6 \\
Pila & 1993-WS & 1.6 & 29.8 & 40.5 \\
IRRI & 1992-WS & 0.0 & 0.0 & 14.3 \\
IRRI & 1993-WS & 5.5 & 52.8 & 55.6 \\
\hline
\end{tabular}

DS, dry season; WS, wet season; -, data not collected or not recorded in detail.

five weeks (Khan et al., 1988; Barrion et al., 1991), and their ability to feed and survive on each stage of the rice plant (Wada, 1979; Chu et al., 1983; Arida et al., 1990). Yet, the observed pattern (fig. 2) indicates the presence of only one, or two overlapping generations. Leaffolder moths emerging from early laid eggs (around five weeks after transplanting) may have contributed to the tail of the egg peak (around 10 weeks after transplanting), but most moths emerging from the egg peak around seven weeks after tranplanting apparently did not oviposit in the same crop. Only in two wet season crops (Pila 91-WS, IRRI 92-WS) was a small second egg peak observed. This means that the majority of the leaffolder larvae originated from immigrant moths, and that population build-up is not expected to occur on a single crop.

The consistent occurrence of the egg peak around the maximum tillering stage suggests that this stage is the most preferred by rice leaffolders for oviposition. Studies on oviposition behaviour of $C$. medinalis moths in Japanese rice fields support this. In a choice situation, $C$. medinalis moths laid most eggs in the tillering crop (Fukamachi, 1980, 1983), and in a no-choice situation, C. medinalis moths emerging after flowering did not oviposit in the same crop but emigrated (Wada et al., 1980; Wada \& Kobayashi, 1982). The oviposition preference is probably related to the quality of the host plant, as rice plants in the ripening stage are less suitable for development and survival of leaffolder larvae (Wada, 1979; Cheng, 1987; Heong, 1990). Also M. patnalis and M. exigua appear to avoid oviposition on a crop after flowering, because in the ripening stage only few eggs of either leaffolder species were found.

Moth and egg density are poor indicators of larval density and the associated level of injury, because no correlations were found between the recruitment levels of moths, eggs and larvae. This confirms the findings of Bandong \& Litsinger (1988), who tested the use of moth density as a basis for leaffolder control decisions, but concluded that it did not perform well. They suggested that the poor value of moth density to predict subsequent injury was caused by the activity of egg predators. In our study, the absence of a correlation between egg and larval density was indeed associated with large variation in survival rates between the crops (table 4). However, the variability in the number of eggs per leaffolder moth may also be explained by moth behaviour. While crops in the tillering stage are favoured for oviposition at night, the moths prefer a more developed crop or a weed vegetation as a habitat during daytime (Fukamachi, 1983; Wada \& Kobayashi, 1991; Miyahara, 1992). In that case, moth density sampled during daytime will be poorly correlated with egg density in the same field.

\section{Species composition of rice leaffolder complex}

The rice leaffolder complex was composed of three species (C. medinalis, M. patnalis, M. exigua), varying in dominance. This is in line with earlier studies in Laguna Province (Arida \& Shepard, 1986; Barrion et al., 1991). 
Table 4. Estimated recruitment per hill of rice leaffolder stages, and stage to stage survival rates.

\begin{tabular}{|c|c|c|c|c|c|c|c|c|c|c|}
\hline \multirow[t]{2}{*}{ Location } & \multirow[t]{2}{*}{ Year-season } & \multicolumn{5}{|c|}{ Recruitment per hill } & \multicolumn{4}{|c|}{ Survival rates } \\
\hline & & Moth & Egg & Larva & Medium & Large & E-L & E-ML & ML-LL & E-LL \\
\hline Victoria & 1991-DS & 0.7 & 9.2 & 4.2 & - & - & 0.46 & - & - & - \\
\hline Pila & 1991-DS & 0.2 & 9.1 & 3.1 & - & - & 0.34 & - & - & - \\
\hline Pila & 1992-DS & 1.3 & 13.9 & 1.3 & 4.4 & 0.4 & 0.09 & 0.31 & 0.09 & 0.03 \\
\hline Pila & 1993-DS & 0.1 & 3.1 & 0.5 & 1.9 & 0.1 & 0.16 & 0.63 & 0.05 & 0.03 \\
\hline Pila & 1991-WS & 0.5 & 6.7 & 3.4 & 7.5 & 2.1 & 0.50 & 1.12 & 0.28 & 0.30 \\
\hline Pila & 1993-WS & 0.2 & 11.2 & 3.5 & 8.0 & 2.0 & 0.31 & 0.72 & 0.25 & 0.18 \\
\hline IRRI & 1992-WS & 1.0 & 4.6 & 0.7 & 0.7 & 0.7 & 0.15 & 0.16 & 0.90 & 0.14 \\
\hline
\end{tabular}

E, egg; L, larva; ML, medium-sized larva; LL, large larva; DS, dry season; WS, wet season; -, larval instars not separately recorded.

Separate analysis of the population dynamics of the three species was hampered by difficulties in the identification of immature stages. As the three species inflict similar injury and share the same natural enemy complex, there seems to be no urgent need for differentiation. The absence of a correlation between egg to larva survival rate and leaffolder species composition per crop (based on moth samples) supports this view. To predict the effect of changes in rice growing practices, such as the introduction of resistant varieties, knowledge about their differential effect per species would nevertheless be needed.

\section{Need for chemical control?}

The question whether the rice leaffolder populations in these untreated fields caused yield losses that justify chemical control cannot be answered directly, because yield loss studies were not included. In the Philippines, recommended action thresholds for rice leaffolder control are 5-15\% injured leaves, or 0.5-1.0 larvae per hill (Bautista et al., 1984; Reissig et al., 1986; Bandong \& Litsinger, 1988). The higher and lower values represent the thresholds during the vegetative and reproductive stage respectively. However, these thresholds have been questioned on empirical and theoretical grounds, and threshold values of 2, and even 5 larvae per hill have been proposed (Smith et al., 1989; Heong, 1993). The larval population stayed below the conservative threshold of 0.5-1.0 larva per hill in three out of eight crops (fig. 2). In the other crops, this threshold was exceeded during the reproductive stage, but in all crops the larval population peak stayed below the level of 2 hill- $^{-1}$.

\section{Why are rice leaffolder densities so low in the Philippines?}

The observations reported here are consistent with the general pattern that emerges from previous studies in insecticide-free rice fields from many different locations and seasons in the Philippines, both in terms of larval phenology and abundance (Kamal, 1981; Guo, 1990; Randriamananoro, 1990; Barrion et al., 1991). The time course and level of the percentage injured leaves was within the range determined by Litsinger et al. $(1987 \mathrm{a}, \mathrm{b})$ in a large-scale yield loss study covering 60 rice crops. The observed levels of larval parasitism and the major species involved also correspond with earlier findings in the Philippines (Kamal, 1981; Arida \& Shepard, 1990; Guo, 1990; Barrion et al., 1991).

Thus, rice leaffolder populations in Philippine rice fields rarely exceed larval densities of 2 hill- $^{-1}$, while the percentage of injured leaves is almost always below 10-15\%. A major explanatory factor for these low population levels might be the relatively late colonization of transplanted rice fields. With an oviposition peak at maximum tillering and avoidance of oviposition after flowering, there is no time for a substantial second generation. Late colonization also implies that most generalist natural enemies are already present and relatively abundant, and may thus cause more mortality. The result is also a relatively low carry-over to other crops of rice (Loevinsohn, 1984). According to this hypothesis, leaffolders could become more damaging when the attractive period for oviposition starts earlier or continues longer. For example, if leaffolders colonize the crop earlier, they might partly escape their natural enemies and there would also be time to reproduce on the same crop. This may be the case in direct seeded rice, where oviposition occurs at a much earlier crop stage compared with transplanted rice, probably due to the higher plant density (Chang, 1993; de Kraker, unpublished). Other examples are rice crops with a long growth duration, prolonging the period for leaffolder oviposition as well. In a long-duration variety with high inputs of nitrogenous fertilizer, two egg peaks were observed before flowering and substantial leaf injury occurred (>30\%, de Kraker, 1996).

\section{Leaffolder survival and the role of natural enemies}

The average survival rate from egg to large larva was $14 \%$ for five crops. The three crops with the lowest survival rates were also those in which leaffolders did not exceed the economic threshold level of 0.5 larvae per hill during the reproductive stage. The observed levels correlate well with the results of a survival analysis conducted by Kamal (1981) in 11 crops of rice at IRRI, who found that survival from egg to large larva was between 12 and $20 \%$. No other field studies on leaffolder survival in tropical Asia have been published. There are strong indications that a large part of the mortality is caused by natural enemies. The estimated survival rates for the field populations were much lower than for leaffolders reared on susceptible varieties when natural enemies were excluded: in greenhouse and field cages larval survival rates were 70-90\% (Waldbauer \& Marciano, 1979; Kamal, 1981; Barrion et al., 1991). The difference in survival between the open field and the cages will mainly be caused by natural enemies, although abiotic factors, like strong wind and rainfall in the wet season or low humidity in the dry season, may have caused some additional mortality in the field. 
Rice leaffolder management can be improved when the effect of natural enemy densities on leaffolder infestations is known. Natural enemy abundance might be accounted for in the threshold for chemical control, or conservation measures could be taken to sustain natural control (Shepard \& Ooi, 1991). However, although the presented data set covers a fairly wide range in leaffolder densities and survival rates, and in levels of parasitism and natural enemy abundance, no clear relationships between these variables were found. This may be due to the generalist nature of most of the predators included in this study, rice leaffolders being only a minor part of their diet. The causes and effects of the diversity and abundance of these generalists will be primarily related to the numerically dominant prey or host species, as has been shown for spiders and hemipteran predators and their homopteran prey species (Kenmore et al., 1984; Heong et al., 1991; Cohen et al., 1994). The same reasoning applies to the parasitoids, as two of the most abundant parasitoid taxa (Cotesia spp. and Tetrastichus spp.) probably included species that have a fairly wide host range. Furthermore, parasitoid species that are not linked to rice leaffolder, but to other, more abundant hosts, may have been included in taxa that were only identified at genus level. This probably was the case with Opius barrioni Fischer (Hymenoptera: Braconidae), a common parasitoid of the abundant rice whorl maggot Hydrellia philippina Ferino (Diptera: Ephydridae). Even in the case of percentage parasitism, which is a more direct approximation of a mortality factor, relationships with leaffolder survival were not clear. The impact of predation was perhaps more important and determined the variation in survival rates.

This study indicates that natural enemies inflict high levels of mortality on leaffolder immatures, but a different approach is needed to answer the question whether and which natural enemies can keep rice leaffolder populations below damaging levels at a given level of egg recruitment. To determine quantitative relationships between natural enemy abundance and leaffolder mortality, more experimental methods are required that study stage survival with known recruitment, and that separate the effects of various mortality factors (van Driesche, 1983; Luck et al., 1988; Bellows et al., 1992). It will also be necessary to identify the major species within the large complex of leaffolder natural enemies, as for these species a relationship between abundance and impact on leaffolder survival can be expected.

\section{Acknowledgements}

Many thanks are due to D. Almario, E. Hernandez, F. de Leon and I. Salon for their technical assistance; A.T. Barrion for taxonomic determinations; and Mrs F. Penaranda for allowing the use of her field throughout the years. G.S. Arida helped to get the field work started. Y.J. Guo, Y.H. Song, R.J. Zhang and M. Nakai are acknowledged for their help in translating Chinese and Japanese publications and T. Wada for the translated chapter of his dissertation. This research was a collaboration between the Wageningen Agricultural University and the International Rice Research Institute, financed by the Netherlands Ministry of International Co-operation (DGIS). The senior author was supported by the Foundation for Biological Research of the Netherlands Organization for Scientific Research (NWO).

\section{References}

Arida, G.S. \& Heong, K.L. (1992) Blower-Vac: a new suction apparatus for sampling rice arthropods. International Rice Research Newsletter 17(6), 30-31.

Arida, G.S., Shepard, M.B. \& Almazan, L.P. (1990) Effect of crop age and leaf location on food consumption and development of rice leaffolder (LF) Marasmia patnalis. International Rice Research Newsletter 15(2), 29.

Arida, G.S. \& Shepard, M. (1986) Seasonal abundance of the rice leaffolder complex in Laguna Province, Philippines. Journal of Agricultural Entomology 3, 382-383.

Arida, G.S. \& Shepard, B.M. (1990) Parasitism and predation of rice leaffolders, Marasmia patnalis (Bradley) and Cnaphalocrocis medinalis (Guenée) (Lepidoptera: Pyralidae) in Laguna province, Philippines. Journal of Agricultural Entomology 7, 113-118.

Bandong, J.P. \& Litsinger, J.A. (1988) Development of action control thresholds for major rice pests. pp. 95-102 in Teng, P.S. \& Heong, K.L. (Eds) Pesticide management and integrated pest management in Southeast Asia. Consortium for International Crop Protection, Maryland, USA.

Barrion, A.T. \& Litsinger, J.A. (1985) Identification of rice leaffolder (LF) by wing markings. International Rice Research Newsletter 10(1), 24.

Barrion, A.T., Litsinger, J.A., Medina, E.B., Aguda, R.M., Bandong, J.P., Pantua, P.C. Jr., Viajante, V.D., de la Cruz, C.G. \& Vega, C.R. (1991) The rice Cnaphalocrocis and Marasmia (Lepidoptera: Pyralidae) leaffolder complex in the Philippines: taxonomy, bionomics and control. Philippine Entomologist 8, 987-1074.

Bautista, R.C., Heinrichs, E.A. \& Rejesus, R.S. (1984) Economic injury levels for the rice leaffolder Cnaphalocrocis medinalis (Lepidoptera: Pyralidae): insect infestation and artificial leaf removal. Environmental Entomology 13, 439-443.

Bellows, T.S. Jr., Van Driesche, R.G. \& Elkinton, J.S. (1992) Life-table construction and analysis in the evaluation of natural enemies. Annual Review of Entomology 37, 587-614.

Chang, P.M. (1993) Rice leaffolder and brown planthopper occurrence in FELCRA Seberang Perak, Malaysia. pp. 14-15 in Research on rice leaffolder management in China. Proceedings of the International Workshop on Economic Threshold Level for Rice Leaffolder in China, Beijing, March 1-2, 1992.

Cheng, C.H. (1987) Investigation on bionomics of the rice leaffolder, Cnaphalocrocis medinalis (Guenée) in the South of Taiwan. Plant Protection Bulletin (Taiwan) 29, 135-146 (in Chinese, English abstract).

Chu, V.I., Ho, K.Y. \& Lee, V.S. (1983) The effect of various host plants on growth and development of the rice leaf roller, (Cnaphalocrocis medinalis (Guenée)). Chinese Journal of Entomology 3, 75-92 (in Chinese, English abstract).

Cohen, J.E., Schoenly, K., Heong, K.L., Justo, H., Arida, G.S., Barrion, A.T. \& Litsinger, J.A. (1994) A food web approach to evaluating the effect of insecticide spraying on insect pest population dynamics in a Philippine irrigated rice ecosystem. Journal of Applied Ecology 31, 747-763.

Dale, D. (1994) Insect pests of the rice plant - their biology and ecology. pp. 363-485 in E.A. Heinrichs (Ed.) Biology and management of rice insects. Wiley Eastern Ltd.

de Kraker, J. (1996) The potential of natural enemies to suppress rice leaffolder populations. PhD thesis, Wageningen Agricultural University, The Netherlands. 
Fukamachi, S. (1980) Habitat and oviposition behavior of the rice leafroller moth, Cnaphalocrocis medinalis, Guenée. Proceedings of the Association for Plant Protection, Kyushu 26, 93-96 (in Japanese).

Fukamachi, S. (1983) Nocturnal activity of the rice leafroller moth, Cnaphalocrocis medinalis, Guenée. Proceedings of the Association for Plant Protection, Kyushu 29, 71-74 (in Japanese).

Guo, Y.J. (1990) Larval parasitization of rice leaffolder (Lepidoptera: Pyralidae) under field and laboratory conditions. PhD thesis, University of the Philippines at Los Baños, Philippines.

Heong, K.L. (1990) Feeding rates of the rice leaffolder, Cnaphalocrocis medinalis (Lepidoptera: Pyralidae), on different plant stages. Journal of Agricultural Entomology 7, $81-90$.

Heong, K.L. (1993) Rice leaffolders: are they serious pests? pp. 8-11 in Research on rice leaffolder management in China. Proceedings of the International Workshop on Economic Threshold Level for Rice Leaffolder in China, Beijing, March 1-2, 1992.

Heong, K.L., Aquino, G.B. \& Barrion, A.T. (1991) Arthropod community structures of rice ecosystems in the Philippines. Bulletin of Entomological Research 81, 407-416.

Heong, K.L., Escalada, M.M. \& Vo Mai (1994) An analysis of insecticide use in rice: case studies in the Philippines and Vietnam. International Journal of Pest Management 40, 173-178.

IRRI (1993) Rice IPM Network - Phase I. Final Report 1990-1993. International Rice Research Institute, Los Baños, Philippines.

Kamal, N.Q. (1981) Suppression of whitebacked planthopper, Sogatella furcifera (Horvath), and rice leaffolder, Cnaphalocrocis medinalis (Guenée), populations by natural enemies. $\mathrm{PhD}$ thesis, Gregorio Araneta University Foundation, Manila, Philippines.

Keller, M.A., Lewis, W.J. \& Stinner, R.E. (1985) Biological and practical significance of movement by Trichogramma species: a review. Southwestern Entomologist, Supplement 8, 138-155.

Kenmore, P.E., Carino, F.O., Perez, C.A., Dyck, V.A. \& Gutierrez, A.P. (1984) Population regulation of the rice brown planthopper (Nilaparvata lugens Stål) within rice fields in the Philippines. Journal of Plant Protection in the Tropics 1, 19-37.

Khan, Z.R., Barrion, A.T., Litsinger, J.A., Castilla, N.P. \& Joshi, R.C. (1988) Mini review: a bibliography of rice leaffolders (Lepidoptera: Pyralidae). Insect Science and its Applications 9, 129-174.

Kulshreshtha, J.P., Kalode, M.B., Prakasa Rao, P.S., Misra, B.C. \& Varma, A. (1970) High yielding varieties and the resulting changes in the pattern of rice pests in India. Oryza 7, 61-64.

Liang, G.W. \& Pang, X.F. (1987) Studies on the life system of rice leafroller. pp. 214-237 in The developments in integrated control of rice diseases and insect pests in China. (in Chinese).

Litsinger, J.A. (1989) Second generation insect pest problems on high yielding rices. Tropical Pest Management 35, 235-242.

Litsinger, J.A., Barrion, A.T. \& Soekarna, D. (1987a) Upland rice insect pests: their ecology, importance, and control. IRRI Research Paper Series 123.

Litsinger, J.A., Canapi, B.L., Bandong, J.P., Dela Cruz, C.G., Apostol, R.F., Pantua, P.C., Lumaban, M.D., Alviola III, A.L., Raymundo, F., Libetario, E.M., Loevinsohn, M.E. \& Joshi, R.C. (1987b) Rice crop loss from insect pests in wetland and dryland environments of Asia with emphasis on the Philippines. Insect Science and its Applications 8, 677-692.

Loevinsohn, M.E. (1984) The ecology and control of rice pests in relation to the intensity and synchrony of cultivation. $\mathrm{PhD}$ thesis, University of London, UK.

Luck, R.F., Shepard, B.M. \& Kenmore, P.E. (1988) Experimental methods for evaluating arthropod natural enemies. Annual Review of Entomology 33, 367-391.

Manly, B.F.J. (1989) A review of methods for the analysis of stage-frequency data. pp. 3-69 in McDowell, L. (Ed.) Estimation and analyses of insect populations. Springer, New York.

Miyahara, V. (1992) Habitats of the rice leafroller moth, Cnaphalocrocis medinalis, Guenée. Proceedings of the Association for Plant Protection, Kyushu 38, 78-81 (in Japanese).

Randriamananoro, J.J. (1990) Colonization of rice leaffolders Cnaphalocrocis medinalis (Guenée) and Marasmia patnalis Bradley (Lepidoptera: Pyralidae) in upland and irrigated rice fields. MSc thesis, University of the Philippines at Los Baños, Philippines.

Reissig, W.H., Heinrichs, E.A., Litsinger, J.A., Moody, K., Fiedler, L., Mew, T.W. \& Barrion, A.T. (1986) Illustrated guide to integrated pest management in rice in tropical Asia. International Rice Research Institute, Los Baños, Philippines.

Shepard, B.M. \& Ooi, P.A.C. (1991) Techniques for evaluating predators and parasitoids in rice. pp. 205-214 in Heinrichs, E.A. \& Miller, T.A. (Eds) Rice insects. management strategies. Springer Series in Experimental Entomology, SpringerVerlag.

Smith, J., Litsinger, J.A., Bandong, J.P. \& Lumaban, M.D. (1989) Economic thresholds for insecticide application to rice: profitability and risk analysis to Filipino farmers. Journal of Plant Protection in the Tropics 6, 67-87.

Southwood, T.R.E. (1978) Ecological methods - with particular reference to the study of insect populations. 2nd edn, Chapman \& Hall.

Van Driesche, R.G. (1983) Meaning of "Percent Parasitism" in studies of insect parasitoids. Environmental Entomology 12, 1611-1622.

Van Driesche, R.G., Bellows, T.S., Elkington, J.S., Gould, J.R. \& Ferro, D.N. (1991) The meaning of Percentage Parasitism revisited: solutions to the problem of accurately estimating total losses from parasitism. Environmental Entomology 20, $1-7$.

Wada, T. (1979) Influence of the temperature and the growing stages of the rice plant on the number of larval instars in the rice leafroller, Cnaphalocrocis medinalis Guenée. Japanese Journal of Applied Entomology and Zoology 23, 178-182 (in Japanese, English abstract).

Wada, T. \& Kobayashi, M. (1980) Effects of temperature on development of the rice leaf roller, Cnaphalocrocis medinalis Guenée (Lepidoptera: Pyralidae). Applied Entomology and Zoology 15, 207-214.

Wada, T. \& Kobayashi, M. (1982) Mating status depending on the growing stage of the rice plant in the population of Cnaphalocrocis medinalis (Guenée). Applied Entomology and Zoology 17, 278-281.

Wada, T. \& Kobayashi, M. (1991) Life history of the rice leaffolder, Cnaphalocrocis medinalis in Japan - invasion, population explosion and dispersal. pp.61-70 in Proceedings of International Seminar on Migration and Dispersal of Agricultural Insects, Tsukuba, Japan, September 1991. 
Wada, T., Kobayashi, M. \& Shimazu, M. (1980) Seasonal changes of the proportions of mated females in the field population of the rice leaffolder, Cnaphalocrocis medinalis Guenée (Lepidoptera: Pyralidae). Applied Entomology and Zoology 15, 81-89.

Waldbauer, G.P. \& Marciano, A.P. (1979) Rice leaffolder: mass rearing and a proposal for screening for varietal resistance in the greenhouse. IRRI Research Paper Series $\mathbf{2 7 .}$

Yoshida, S. (1981) Fundamentals of rice crop science. International Rice Research Institute, Los Baños, Philippines.
Zhang, X.X. (1991) Migration of rice leaf roller, Cnaphalocrocis medinalis Guenée, in China. pp. 51-60 in Proceedings of International Seminar on Migration and Dispersal of Agricultural Insects, Tsukuba, Japan, September 1991.

(Accepted 17 August 1999) (C) CAB International, 1999 
v- onportunity.

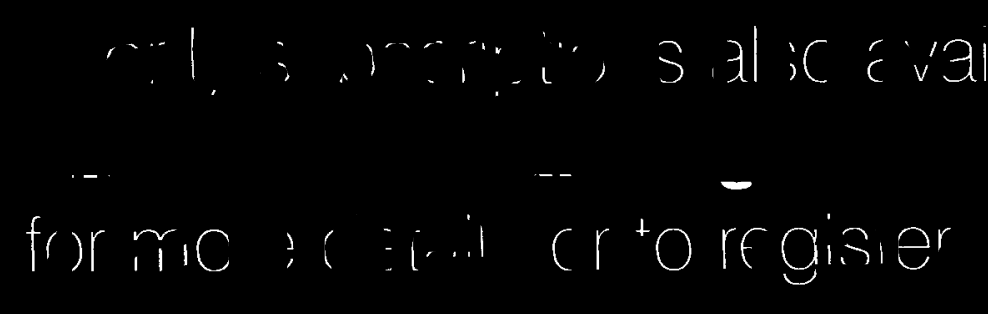

The Internet version will be exactly the same as the print and will includer

- Contents page

- Full text of original research papers and review articles

- Short communications

- Aims \& bscope

- Submission instructioins for authors

- Supplements and special issues (when published)

- Links from cited references to bibliographic databases

$$
\text { special offer for } \mathbf{2 0 0 0}
$$

Organizations with print subscriptions get FREE sitewide access to the Internet version of this title 